\title{
The Effect of Outcome Therapy to the Quality of Life Type 2 Diabetes Mellitus Patient on West Nusa Tenggara Hospital, Indonesia
}

\author{
Wirawan Adikusuma*, Baiq Leny Nopitasari \\ Department of Pharmacy, Faculty of Health Science, University of Muhammadiyah Mataram, Mataram, INDONESIA.
}

\begin{abstract}
Background: Diabetes is a chronic disease that requires long-term treatment. The results of therapy will indirectly affect the quality of life of patients with diabetes mellitus. This study was done to determine the effect of therapeutic results on the quality of life of patients with type 2 diabetes mellitus (T2DM). Methods: This study uses a cross-sectional design. The inclusion criteria of this study were T2DM patients aged $45-65$ years with ICD code X E. 11 and the subjects in this study involved 60 T2DM outpatients. This study was divided into 2 groups (oral hypoglycaemic and insulin group). Quality of life data was collected using the SF 36 questionnaire. Results: The results of this study showed no significant differences between the quality of life of T2DM patients in both groups. There were a significant relationship between Physical functioning domain with $\mathrm{HbA1c}$ and FBG, emotional domain with $\mathrm{HbA} 1 \mathrm{c}$, general health domain with $\mathrm{FBG}$, physical
\end{abstract}

role domain with $\mathrm{FBG}$, mental health domain with $\mathrm{HbA} 1 \mathrm{c}$ and bodily pain domain with $\mathrm{HbA1C}$ and FBG. Conclusion: Outcome therapy affects the quality of life of T2DM patients in $\mathrm{HbA} 1 \mathrm{C}$ and FBG.

Key words: Outcome therapy, Quality of life, SF-36, Type 2 diabetes mellitus, Indonesia.

\section{Correspondence}

Mr. Wirawan Adikusuma

Department of Pharmacy, Faculty of Health Science, University of Muhammadiyah Mataram, Mataram-83127, INDONESIA.

Phone: 62-81-915848228

Email: adikusuma28@gmail.com

DOI: 10.5530/jyp.2019.11.59

\section{INTRODUCTION}

Type 2 diabetes mellitus (T2DM) is a chronic, non-curable chronic disease that can reduce Health-Related Quality of Life (HRQOL) and cause less optimal physical and mental function and premature death. ${ }^{1,2}$ The prevalence of people with diabetes in Indonesia shows a tendency to increase, from $5.7 \%$ (2007) to $6.9 \%$ (2013). In 2015, Indonesia was ranked seventh in the world for the highest diabetics in the world along with China, India, the United States, Brazil, Russia and Mexico with an estimated 10 million people with diabetes. ${ }^{3}$

Diabetic patients need continuous therapy so that the effectiveness and side effects of treatment can affect the quality of life. ${ }^{4}$ Quality of life is a health outcome related to the patient's condition from psychological, social and emotional perspectives. ${ }^{5}$ HRQOL refers to the physical, psychological and social health domains that are influenced by one's experience, beliefs, expectations and perceptions, therefore health care providers must strive to understand the physical, emotional and social effects of chronic diseases such as diabetes. ${ }^{6}$ Many factors that affect the quality of life of patients with diabetes mellitus include complications, hypertension, duration of diabetes, physical exercise, diet with more red meat, diet control, glucose check frequently and depression. ${ }^{5-7}$ Quality of life has become a relevant measurement tool in clinical trials, its use is increasingly widespread and developing as a valid and beneficial indicator in a medical study. Quality of life can be seen from an individual, group and large population of patients. ${ }^{8}$

Quality of life can be measured by instruments such as questionnaires. Short Form-36 (SF-36) is one instrument that can be used to measure the quality of life, practical and has good psychometric properties. ${ }^{9} \mathrm{SF}$ 36 has been widely used with clinical studies involving a diverse population of patients by assessing eight health concepts. ${ }^{10}$ This study aimed to determine the effect of outcome therapy on the quality of life-based on SF 36 in patients with T2DM.

\section{MATERIALS AND METHODS}

A cross-sectional study was carried out in West Nusa Tenggara Hospital during April-July 2017 in T2DM outpatients. The inclusion criteria were T2DM patients received oral antidiabetics or insulin at least 6 months with ICD code X E.11 before quality of life measurements and were willing to sign the informed consent form. Exclusion criteria are deaf patient, illiterate and pregnant patient. Subjects who met the inclusion criteria were $60 \mathrm{~T} 2 \mathrm{DM}$ patients. They were classified into two groups namely: (i) oral antidiabetic therapy and (ii) insulin therapy. This research has been approved by the ethics committee of West Nusa Tenggara Hospital, Indonesia.

Quality of life was measured by using an Indonesian version of ShortForm 36 (SF-36) has been validated. Validation the questionnaire was carried out via conducting a pilot study. The pilot study was conducted with 20 patients. The reliability analysis of the questionnaire was performed by calculating Cronbach alpha value. The results of the validity and reliability test of the SF-36 questionnaire to measure the quality of life in 20 T2DM can be seen in Table 1. The domain which includes the SF-36 were domains of physical functioning, role physical, bodily pain, general health, vitality, social functioning, role emotional and mental health. The item and scale of the SF- $36^{\circ}$ Health Survey were built by using the like method of the summed rank. Answers for each question are given scoring. This score is then added to generate a standard score scale for each later health concept transformed to a scale of $0-100$, with a value of 100 as a quality of life best. ${ }^{11}$ 
Table 1: Validity and reliability test results of the SF-36 health questionnaire survey.

\begin{tabular}{|c|c|c|c|c|c|}
\hline Domain & $\begin{array}{l}\text { Question } \\
\text { item }\end{array}$ & $r$-count & Criteria & $\begin{array}{c}\text { Reliability } \\
\text { Cronbach's } \\
\text { alpha }\end{array}$ & Criteria \\
\hline \multirow{6}{*}{$\begin{array}{l}\text { General } \\
\text { health }\end{array}$} & Q1 & 0,555 & Valid & \multirow{6}{*}{0.707} & Reliable \\
\hline & Q2 & 0,718 & Valid & & Reliable \\
\hline & Q33 & 0,637 & Valid & & Reliable \\
\hline & Q34 & 0,571 & Valid & & Reliable \\
\hline & Q35 & 0.626 & Valid & & Reliable \\
\hline & Q36 & 0,703 & Valid & & Reliable \\
\hline \multirow{10}{*}{$\begin{array}{l}\text { Physical } \\
\text { functioning }\end{array}$} & Q3 & 0,492 & Valid & \multirow{10}{*}{0.731} & Reliable \\
\hline & Q4 & 0,523 & Valid & & Reliable \\
\hline & Q5 & 0,715 & Valid & & Reliable \\
\hline & Q6 & 0,720 & Valid & & Reliable \\
\hline & Q7 & 0,796 & Valid & & Reliable \\
\hline & Q8 & 0,502 & Valid & & Reliable \\
\hline & Q9 & 0,644 & Valid & & Reliable \\
\hline & Q10 & 0,906 & Valid & & Reliable \\
\hline & Q11 & 0,906 & Valid & & Reliable \\
\hline & Q12 & 0,853 & Valid & & Reliable \\
\hline \multirow{4}{*}{ Role physical } & Q13 & 0.759 & Valid & \multirow{4}{*}{0.932} & Reliable \\
\hline & Q14 & 0.843 & Valid & & Reliable \\
\hline & Q15 & 0.919 & Valid & & Reliable \\
\hline & Q16 & 0.851 & Valid & & Reliable \\
\hline \multirow{3}{*}{$\begin{array}{c}\text { Role } \\
\text { emotional }\end{array}$} & Q17 & 0.734 & Valid & \multirow{3}{*}{0.914} & Reliable \\
\hline & Q18 & 0.856 & Valid & & Reliable \\
\hline & Q19 & 0.903 & Valid & & Reliable \\
\hline \multirow{2}{*}{$\begin{array}{c}\text { Social } \\
\text { functioning }\end{array}$} & Q20 & 0.746 & Valid & \multirow{2}{*}{0.854} & Reliable \\
\hline & Q32 & 0.746 & Valid & & Reliable \\
\hline \multirow{2}{*}{ Bodily pain } & Q21 & 0.903 & Valid & \multirow{2}{*}{0.943} & Reliable \\
\hline & Q22 & 0.903 & Valid & & Reliable \\
\hline \multirow{4}{*}{ Vitality } & Q23 & 0.551 & Valid & \multirow{4}{*}{0.718} & Reliable \\
\hline & Q27 & 0.610 & Valid & & Reliable \\
\hline & Q29 & 0.570 & Valid & & Reliable \\
\hline & Q31 & 0.626 & Valid & & Reliable \\
\hline \multirow{5}{*}{ Mental health } & Q24 & 0.506 & Valid & \multirow{5}{*}{0.856} & Reliable \\
\hline & Q25 & 0.928 & Valid & & Reliable \\
\hline & Q26 & 0.913 & Valid & & Reliable \\
\hline & Q28 & 0.881 & Valid & & Reliable \\
\hline & Q30 & 0.396 & Valid & & Reliable \\
\hline
\end{tabular}

Data collection was done by an interview with SF-36 questionnaire and medical records or patient status which include name, age, gender, diagnosis, treatment and laboratory data. Data were analyzed descriptively to describe patients' characteristics. The Independent sample t-test was used to analyze the difference of quality of life domains differences among the two groups and linear regression analysis was conducted to analyze the association between patient's quality of life and outcome therapy T2DM patients.

\section{RESULTS}

T2DM patients who met the inclusion and exclusion criteria in this study were 60 people. Table 2 shows list the subject characteristics. Most of the study subject were female (61.67\%), had an education level up to senior high school $(80 \%)$, was aged $\geq 55$ years $(61.67 \%)$, who had occupation (68.33\%), had an average treatment duration of more than equal 5 years

\begin{tabular}{cccc} 
Table 2: Subject characteristic. & & \\
\hline \multicolumn{2}{c}{ Characteristic } & N & $\%$ \\
\hline Gender & Male & 23 & 38.33 \\
& Female & 37 & 61.67 \\
Education & Up to Senior High & 48 & 80.00 \\
& School & & \\
& Undergraduate & 12 & 20.00 \\
Age & $<55$ years old & 23 & 38.33 \\
& $\geq 55$ years old & 37 & 61.67 \\
Occupation & Jobless & 19 & 31.67 \\
& Occupied & 41 & 68.33 \\
Treatment duration & $<5$ years & 21 & 35.00 \\
in years & & & \\
& $\geq 5$ years & 39 & 65.00 \\
Treatment & Oral antidiabetic & 27 & 45.00 \\
& Insulin & 33 & 55.00 \\
\hline
\end{tabular}

Table 3: Quality of Life Domains Differences between Treatment Groups.

\begin{tabular}{cccc}
\hline \multirow{2}{*}{ Domain } & \multicolumn{2}{c}{ Therapy } & \\
\cline { 2 - 3 } & $\begin{array}{c}\text { Oral } \\
\text { hypoglicemic }\end{array}$ & Insulin & P Value \\
\hline Physical functioning & $76.85 \pm 30.00$ & $76.81 \pm 30.48$ & 0.921 \\
Role emotional & $70.07 \pm 27.78$ & $63.27 \pm 25.52$ & 0.328 \\
Social functioning & $84.00 \pm 26.43$ & $91.60 \pm 17.15$ & 0.204 \\
General health & $74.77 \pm 11.69$ & $72.36 \pm 12.71$ & 0.451 \\
Role physical & $76.85 \pm 42.13$ & $71.21 \pm 41.51$ & 0.402 \\
Mental health & $76.51 \pm 42.18$ & $68.66 \pm 44.83$ & 0.444 \\
Bodily pain & $68.00 \pm 27.05$ & $65.93 \pm 29.45$ & 0.850 \\
Vitality & $50.74 \pm 28.34$ & $48.03 \pm 29.23$ & 0.731 \\
Average of QoL & $71.85 \pm 20.65$ & $69.33 \pm 19.61$ & 0.631 \\
\hline
\end{tabular}

(65\%) and the dominant treatment was insulin therapy (55\%). Table 3 show quality of life domains differences between treatment groups. The analysis show there were not significant among two groups in each domain quality of life. Table 4 show the results of linear regression analysis the association between patients' quality of life and outcome therapy T2DM patients. The results of the analysis indicate that quality of life can affect the outcome therapy such as HbAlc and FBG.

\section{DISCUSSION}

In this study, there were $60 \mathrm{~T} 2 \mathrm{DM}$ patient's outpatient in the provincial West Nusa Tenggara hospitals in April-July 2017 who were interviewed regarding the quality of life. Based on the results of the study, the average quality of life of patients receiving oral hypoglycemic has a higher quality of life $(71.85 \pm 20.65)$ than patients who received insulin $(69.33 \pm 19.61)$. However, statistically using the independent sample $t$-test showed no significant differences $(p=0.631)$.

The measurement of quality of life with SF-36 in this study includes eight domains, namely physical functioning, role physical, bodily pain, general health, vitality, social functioning, role emotional and mental health. ${ }^{12}$ The results of measurements of quality of life in this study based on each domain showed no significant differences between the two groups. In contrast to previous studies using the Diabetes Quality of Life Clinical Trial Questionnaire (DQLCTQ) to measure the quality of life of T2DM 
Table 4: Linear Regression Analysis Results between Quality of Life and Outcome Therapy.

\begin{tabular}{cccc}
\hline Domain & HbA1c & FBG & 2-h PG \\
\hline Physical functioning & $0.023^{*}$ & $0.007^{*}$ & 0.490 \\
Role emotional & $0.006^{*}$ & 0.199 & 0.619 \\
Social functioning & 0.629 & 0.385 & 0.495 \\
General health & 0.061 & $0.003^{*}$ & 0.477 \\
Role physical & 0.053 & $0.013^{*}$ & 0.985 \\
Mental health & $0.024^{*}$ & 0.086 & 0.571 \\
Bodily pain & $0.049^{*}$ & $0.004^{*}$ & 0.545 \\
Vitality & 0.077 & 0.439 & 0.541 \\
Average of QoL & $0.003^{*}$ & $0.004^{*}$ & 0.980 \\
\hline
\end{tabular}

${ }^{*} p$ value $<0.05$.

patients, there were differences between the three therapy groups used in the domain of a physical function, energy, satisfaction and treatment effects. ${ }^{13}$

Anti-diabetes therapy can affect the quality of life both negatively and positively. negatively impact can improve symptoms of low blood sugar and positively impact can reduce symptoms of high blood sugar. ${ }^{14,15}$ HbA1c, FBG and 2H PG are the most widely used clinical indicators for diabetic patients. ${ }^{16}$ This study shows that there were a relationship between $\mathrm{HbAlc}$ and FBG on the quality of life of T2DM patients, different from previous studies, there was a statistically significant relationship between the results of therapy (2H PG) and the quality of life of diabetic patients. ${ }^{17} \mathrm{HbAlc}$ and FBG were not accurate to represent the level of blood sugar control because they do not reflect what happens after eating. 2H PG has a strong correlation with microvascular, macrovascular and cardiovascular compared to HbAlc and FBG. ${ }^{18}$ However, the American Diabetes Association recommends measuring $\mathrm{HbAlc}$ as a substitute for fasting blood glucose for the diagnosis of diabetes. HbAlc is an important indicator for seeing long-term glycemic control up to three months earlier. $^{19,20}$

Blood sugar levels can affect the quality of life, the more controlled blood sugar levels, the better the quality of life for T2DM patients. ${ }^{21}$ In addition, controlling blood sugar levels is very important to measure the quality of life of T2DM patients because it can affect the functional health, psychological and social of patients. ${ }^{22}$ The limitation of this study is the limited number of research samples and requires a long time to explain the contents of the questionnaire to patients.

\section{CONCLUSION}

We found that HbA1c and FBG can affect the quality of life of T2DM patients.

\section{ACKNOWLEDGEMENT}

The authors wish to thank all the study participants for their cooperation and this research was funded by a University of Muhammadiyah Mataram, Indonesia grant.

\section{CONFLICT OF INTEREST}

The authors declare no conflict of interest.

\section{ABBREVIATIONS}

T2DM: Type 2 diabetes mellitus; ICD: International Classification of Diseases; SF 36: Short-Form 36; HbA1c: Hemoglobin A1c; FBG: Fasting Blood Glucose; HRQOL: Health-Related Quality of Life; DQLCTQ: Diabetes Quality of Life Clinical Trial Questionnaire; 2-h PG: 2 hour plasma glucose; QOL: Quality of Life.

\section{REFRENCES}

1. Cong JY, Zhao $Y, X u Q Y$, DeZhong $C$, Xing $Q L$. Health-related quality of life among Tianjin Chinese patients with type 2 diabetes: A cross-sectional survey. Nurs Heal Sci. 2012;14(4):528-34. doi:10.1111/j.1442-2018.2012.00734.x

2. Scollan-Koliopoulos M, Bleich D, Rapp KJ, Wong P, Hofmann CJ, Raghuwanshi M. Health-Related Quality of Life, Disease Severity and Anticipated Trajectory of Diabetes. Diabetes Educ. 2013;39(1):83-91. doi:10.1177/0145721712467697

3. International Diabetes Federation. IDF Diabetes Atlas-Seventh Edition. 2015 doi:10.1289/image.ehp.v119.i03

4. Adikusuma W, Perwitasari D, Supadmi W Evaluasi Kualitas Hidup Pasien Diabetes Melitus Tipe 2 Rumah Sakit Umum PKU Muhammadiyah Bantul. Pros Simp Nas Peluang Dan Tantangan Obat Tradis Dalam Pelayanan Kesehat Form. 2014;(January):32-9. doi:10.3934/dcdsb.2011.15.1

5. Al-Shehri AH, Taha AZ, Bahnassy AA, Salah M. Health-related quality of life in type 2 diabetic patients. Ann Saudi Med. 2008;121(06):439-44. doi:10.1016/j. wneu.2017.02.094

6. Camacho F, Anderson RT, Bell RA, et al. Investigating correlates of health related quality of life in a low-income sample of patients with diabetes. Qual Life Res. 2002;11(8):783-96. doi:10.1023/A:1020858102483

7. Jing $X$, Chen J, Dong $Y$, et al. Related factors of quality of life of type 2 diabetes patients: A systematic review and meta-analysis. Health Qual Life Outcomes. 2018;16(1):189. doi://dx.doi.org/10.1186/s12955-018-1021-9

8. Spilker B. Quality of life and clinical trials. Lancet. 1995;346(8966):1-2 doi:10.1016/S0197-2456(97)82191-5

9. Ware JE, Snow KK, Kosinski M, Gandek B. SF-36 Health Survey Manual and Interpretation Guide. 1993.

10. Ware JE. SF-36 Health Survey Update. Proc $201212^{\text {th }}$ Int Conf Hybrid Intell Syst HIS 2012. 2012;25(24):47-51. doi:10.1109/HIS.2012.6421307

11. Ware JE, Highway GW, Highway GW. SF-36 ${ }^{\circledR}$ Health Survey (Version 1.0). CHSD Univ Wollongong. 2014;1-15. doi:10.5772/46004

12. Ware JE, Kosinski M, Keller SD. SF-36 Physical and Mental Health Summary Scales: a User Manual. $5^{\text {th }}$ ed. Boston: MA: HEalth Assessment Lab. 1994

13. Perwitasari D, Adikusuma W, Rikifani S, Supadmi W, Kaptein A. Quality of Life and Adherence of Diabetic Patients in Different Treatment Regimens. Indones J Clin Pharm. 2014;3(4):107-13. doi:10.15416/ijcp.2014.3.4.107

14. Uni M, Sciences $\mathrm{HH}$, Miller ME, et al. Long-term Effects of Intensive Glucose Lowering on Cardiovascular Outcomes. N Engl J Med. 2011;364(9):818-28. doi:10.1056/NEJMoa1006524

15. Wexler DJ, Grant RW, Wittenberg E, et al. Correlates of health-related quality of life in type 2 diabetes. Diabetologia. 2006;49(7):1489-97. doi:10.1007/s00125006-0249-9

16. Hu M, Zhou Z, Zeng F, Sun Z. Effects of Frequency of Follow-Up on Quality of Life of Type 2 Diabetes Patients on Oral Hypoglycemics. Diabetes Technol Ther. 2012;14(9):777-82. doi:10.1089/dia.2012.0037

17. Perwitasari DA, Urbayatun S, Faridah IN, Masyithah N. Relationship of therapeutic outcome with quality of life on type 2 diabetes mellitus patients in Abdul Azis Singkawang hospital Relationship of therapeutic outcome with quality of life on type 2 diabetes mellitus patients in Abdul Azis Singkawang hospital. IOP Conf Ser Mater Sci Eng. 2017;259(1):1-8. doi:10.1088/1757-899X/259/1/012023

18. Myers VH, McVay MA, Brashear MM, et al. Exercise training and quality of life in individuals with type 2 diabetes. Diabetes Care. 2013:36(7):1884-90. doi:10.2337/dc12-1153

19. ADA. Position statement: Standar of Medical Care in Diabetes 2014. Diabetes Care. 2014;37(1):S14-80. doi:10.2337/dc14-S014

20. Sherwani SI, Khan HA, Ekhzaimy A, Masood A, Sakharkar MK. Significance of $\mathrm{HbA} 1 \mathrm{c}$ test in diagnosis and prognosis of diabetic patients. Biomark Insights. 2016;11:95-104. doi:10.4137/Bmi.s38440

21. Khanna A, Bush AL, Swint JM, Peskin MF, Street RL, Naik AD. Hemoglobin A1c improvements and better diabetes-specific quality of life among participants completing diabetes self-management programs: a nested cohort study. Health Qual Life Outcomes. 2012;10(1):48. doi:10.1186/1477-7525-10-48

22. Zurdayanis, Marfianti E. Hubungan Kadar Glukosa Darah dengan Kualitas Hidup pada Pasien Diabetes Melitus Tipe II di RSUD Sleman Yogyakarta. J Kedokt dan Kesehat Indones. 2010;2(6):31-5.

Article History: Submission Date : 19-02-2019; Revised Date : 28-05-2019; Acceptance Date : 29-05-2019.

Cite this article: Adikusuma W, Nopitasari BL. The Effect of Outcome Therapy to the Quality of Life Type 2 Diabetes Mellitus Patient on West Nusa Tenggara Hospital, Indonesia. J Young Pharm. 2019;11(3):297-9. 